\title{
Desenvolvimento Infantil Saudável: Projeto Ensinando a Crescer
}

\author{
Talita Albuquerque Franco ${ }^{1}$; Gustavo Henrique Silva Alencar Luna. ${ }^{2}$; José Jayslânio Rosado Matias ${ }^{3}$; \\ Francinete Alves de Oliveira Giffoni ${ }^{4 ;}$ Joelma dos Santos Barbosa Linhares Garcia ${ }^{5}$
}

\begin{abstract}
Resumo: O presente trabalho se propõe a avaliar a importância do projeto de extensão Ensinando a crescer para a sociedade barbalhanse no ano de 2013. Tal projeto foi desenvolvido por acadêmicos da Universidade Federal do Ceará na tentativa de garantir o desenvolvimento pediátrico saudável, em todos os seus aspectos, para a minimização dos efeitos maléficos à saúde do adulto. Uma criança bem assistida tende a apresentar melhor desempenho físico-mental ao longo de sua vida, influenciando positivamente no seu sucesso sócio-educacional. As atividades ocorrem na EEFM Maria da Dores, localizada em Barbalha. Em suma, são realizadas palestras para os pais e cuidadores de crianças, ministradas pelos alunos integrantes do projeto e por profissionais de saúde convidados, onde são discutidos os diversos temas inerentes à saúde da criança. Para analisar quantitativa e qualitativamente a importância do projeto em discussão, foi elaborado um questionário composto por quatro questões objetivas, aplicado, no fim de cada encontro, aos participantes. Dentre os questionamentos, todos (100\%) julgaram haver melhorado o cuidado com seu f ilho após as palestras. Através deste estudo, percebe-se o quanto é válida a realização de atividades extensionistas desta natureza.
\end{abstract}

Palavras-chave: criança; extensão; saúde

\section{Healthy Child Development: Teaching Growing up Project}

\begin{abstract}
The present study aims to evaluate the importance of the extension project: Teaching to grow up, to barbalhanse society in 2013. This project was developed by academics from the Federal University of Ceará in an attempt to ensure the healthy pediatric development in all its aspects, for minimizing the harmful effects on adult health. A well cared children tend to have better physical and mental over your life performance, positively influencing the socio-educational success. Activities take place in EEFM Maria das Dores, located in Barbalha. In sum, lectures for parents and caregivers of children, taught by members of the project students and health professionals invited, where they discuss various issues related to the health of children are held. To analyze quantitatively and qualitatively the importance of the project under discussion, we create a questionnaire consists of four objective questions, applied at the end of each meeting, to the participants _ . Among the questions, all $(100 \%)$ they judged improved care for their son after the lectures. Through this study, it can be seen how valid is conducting extension activities of this nature.
\end{abstract}

Keywords: child; extension; health

\footnotetext{
${ }^{1}$ Acadêmica de Medicina, Universidade Federal do Ceará, Barbalha, Ceará. E-mail: talita_albuquerque@hotmail.com

${ }^{2}$ Acadêmico de Medicina, Universidade Federal do Ceará, Barbalha, Ceará. E-mail: gustavohsal@gmail.com

${ }^{3}$ Acadêmico de Medicina, Universidade Federal do Ceará, Barbalha, Ceará. E-mailjjmatias12@ hotmail.com

${ }^{4}$ Professora da Universidade Federal do Ceará. E-mail: francinetealves@gmail.com

${ }^{5}$ Mestranda em Ciências da Educação pela Universidade San Carlos - PY. E-ail: jsblinharesgarcia@hotmail.com
} 


\section{Introdução}

Como todo país subdesenvolvido, o Brasil enfrenta graves problemas da ordem socioeconômica. Dentre as nações do planeta, aqui ainda mantém uma das mais injustas desigualdade social, onde uma minoria concentra em suas mãos, a maior parte da renda per capita, ficando boa parte da população subjugada a viver sob condições de miséria. E é nesse contexto que estão crescendo as crianças brasileiras (SANTOS e KASSOUF, 2007).

A problemática do Brasil remonta ao período colonial, quando aos colonos restava a submissão ao seu senhor - a ele, os colonos destinavam todo seu trabalho e fidelidade.

Enquanto os filhos de famílias abastadas iam estudar na Europa, os dos colonos iam trabalhar com seus pais no campo, por exemplo, buscando aumentar a produtividade do patrão. Com o passar dos tempos, a sociedade evoluiu. A escravidão no Brasil foi extinta. As relações trabalhistas modificaram-se e, o proletariado tem conquistado maior espaço a cada dia, garantindo seus direitos de trabalho. A desigualdade social, no entanto, parece ter-se perpetuado (CATTANI e KIELING, 2007).

Ao longo dos anos, os administradores do Brasil pouco investiram em educação. Parece não haver interesse da classe política na formação de uma população esclarecida, capaz de por em risco os privilégios de seus mandatários. Daí vivermos em meio a tantos problemas sociais.

Uma das situações mais preocupante, é o fato de que a cada dia, as crianças pobres são mais afetadas pelo sistema. A elas são negadas condições mínimas de subsistência, além de tornarem-se dependentes de sistemas públicos de saúde e educação, que não são adequados às crescentes necessidades de uma população que cresce em ritmo exponencial.

Não obstante, vale salientar que, em muitas vezes, são também vítimas da violência doméstica e/ou social. Considerados juridicamente como seres incapazes, tornam-se presas fáceis para adentrar no mundo das drogas, do crime e da prostituição (NELSON et al, 2009).

Foi baseado na argumentação supracitada que, acadêmicos da Universidade Federal do Ceará - campus Cariri resolveram desenvolver o projeto de extensão Ensinando a Crescer, na tentativa de refletir a importância de se garantir um desenvolvimento infantil saudável, em todos os seus aspectos. O objetivo foi a minimização dos efeitos maléficos à saúde do futuro adulto.

Uma criança bem assistida tende a apresentar um melhor desempenho físico-mental ao longo de sua vida, o que certamente influenciará positivamente no seu sucesso educacional (FERREIRA, FERREIRA e ALVES, 1996; MARCONDES, 2003) . Daí o valor de se desenvolver trabalhos visando o fornecimento, aos pais e cuidadores de crianças, através de informações indispensáveis à promoção da saúde da população infantil. 
O projeto Ensinando a crescer conta com a participação de quatro acadêmicos e é coordenado por um docente da Universidade Federal do Ceará - campus Cariri.

As atividades ocorrem na Escola de Ensino Fundamental e Médio Maria da Dores Sampaio, localizada em Barbalha.

As atividades constam de palestras aos pais e cuidadores de crianças, bem como professores e servidores da unidade de ensino. São ministradas pelos estudantes vinculados ao Projeto e, por profissionais de saúde e/ou educação, convidados exclusivamente para esta finalidade. Nestas ocasiões são discutidos temas diversos relacionados a saúde da criança, a saber:

- Papel dos pais e cuidadores no desenvolvimento psicopedagógico da criança

- Calendário vacinal

- Alimentação na infância

- Crescimento e desenvolvimento

- Prevenção de acidentes

- Doenças prevalentes da infância (Infecções das Vias Aéreas Superiores - IVAS)

- Pneumonia e diarréias agudas

- Saúde bucal - atenção odontológica na primeira infância

A Psicologia da Saúde, tem um papel importante de buscar uma compreensão dos aspectos psíquicos e sociais relacionados ao ser humano, de maneira a melhoria sua assistência integral. Além disso, autores como Suls e Rothman (2004), Brown e Folen (2005), consideram que a educação em saúde, tem a função de auxiliar na prevenção e no controle dos sintomas que possam vir a prejudicar o bem-estar das pessoas.

O presente estudo teve o objetivo de avaliar a importância do Projeto de extensão Ensinando a Crescer, para a sociedade barbalhanse no ano de 2013.

\section{Método}

Para analisar quantitativa e qualitativamente a importância do projeto em discussão, foi elaborado um questionário composto por quatro questões objetivas, aplicado junto aos participantes, ao final de cada encontro. 
A amostra constou de 70 indivíduos que responderam ao questionário, no período de maio a setembro de 2013.

\section{Resultados}

A tabela 1 mostra a distribuição dos 70 participantes de acordo com o papel desempenhado na vida das crianças (pais/cuidadores).

Tabela 1 - Distribuição por papel desempenhado na vida da criança

\begin{tabular}{c|c}
\hline $\begin{array}{c}\text { Função(pai/cuidador } \\
\text { de criança) }\end{array}$ & $\begin{array}{c}\text { Porcentagem (participantes do } \\
\text { projeto) }\end{array}$ \\
\hline Cuidador & $\mathbf{1 4 , 2 8}(10 / 70)$ \\
\hline Pai & $\mathbf{8 5 , 7 1}(60 / 70)$ \\
\hline
\end{tabular}

$\mathrm{Na}$ assistência a crianças é fundamental, além do conhecimento sobre desenvolvimento da infância, que os pais e familiares estejam atentos para as questões relacionadas à sua saúde de maneira integral, bem como para ações preventivas.

Mello (1992) destaca que é fundamental que se estabeleça uma troca de conhecimentos entre a escola e a família, nas discussões sobre problemas relacionados ao seu desenvolvimento. Além disso, é muito importante destacar a postura do profissional que cuida, na forma como este interage com a criança e com a sua família. Pois, o autor acredita que, uma atitude acolhedora e afetiva, que pode ser demonstrada até através do olhar, do tom de voz, ou do toque, pode estabelecer e/ou o vínculo terapêutico mais eficaz. .

A tabela 2 faz referência à nota dada às palestras em geral.

Quando indagado a eles se consideravam importante o conhecimento sobre as doenças mais comuns na infância, $100 \%$ responderam sim. Somado a isso, todos (100\%) julgaram haver melhorado o cuidado com seu filho após as palestras. 
Tabela 2 - Nota dada às palestras ministradas durante o período de maio a setembro de 2013

\begin{tabular}{l|c}
\hline Nota das palestras & $\begin{array}{c}\text { Porcentagem } \\
\text { (participantes do } \\
\text { projeto })\end{array}$ \\
\hline Maior que 8 & $\mathbf{8 1 , 4 3 \%}(57 / 70)$ \\
\hline Entre 5 e 8 & $\mathbf{1 8 , 5 7 \% ( 1 3 / 7 0 )}$ \\
\hline Menor que 5 & $-\cdots---$ \\
\hline
\end{tabular}

Educação em Saúde na Escola, principalmente para pais, significa a formação de atitudes e valores que possam levar a práticas mais conducentes à saúde. Deve estar integrada à educação global e presente em todos os aspectos da vida do escolar e da sua família.

A preparação adequada do pessoal que participa de um programa de educação em saúde na escola é indispensável para assegurar seu êxito.

Segundo a Organização Pan-americana de Saúde (1995), a promoção da saúde precisa partir de uma visão integral e multidisciplinar da pessoa humana. Isso significa considerar o contexto familiar, social, comunitário e, ambiental. Portanto, as ações de educação em saúde, visam desenvolver conhecimentos e habilidades de autocuidados, bem como uma prevenção em termos de condutas de risco em qualquer oportunidade educativa.

Segundo Pelicioni (1999), é importante fomentar valores, condutas, condições sociais e estilos de vida mais alinhados com hábitos saudáveis.

Por último, foi questionada a importância do fortalecimento de um bom relacionamento entre pais e cuidadores de crianças para o desenvolvimento psíquico e social delas. A tabela 3 mostra os resultados $-40 \%(28 / 70)$ o julgou importante, enquanto que 60\%(53/70), extremamente importante.

Tabela 3 - Avaliação da importância do fortalecimento da relação entre pais e cuidadores de crianças

\begin{tabular}{l|c}
\hline $\begin{array}{c}\text { Fortalecimento da } \\
\text { relação pai-cuidador }\end{array}$ & $\begin{array}{c}\text { Porcentagem } \\
\text { (participantes do } \\
\text { projeto) }\end{array}$ \\
\hline $\begin{array}{l}\text { Extremamente } \\
\text { importante }\end{array}$ & $\mathbf{6 0 \%}(42 / 70)$ \\
\hline Importante & $\mathbf{4 0 \% ( 2 8 / 7 0 )}$ \\
\hline Sem importância & $-\cdots---$ \\
\hline
\end{tabular}




\section{Conclusões}

Os profissionais de saúde precisam estar atentos para a participação dos pais ou responsáveis quanto ao cuidado da criança. Uma equipe madura para esse tipo de comunicação tende a conquistar a contribuição da família em relação aos cuidados com a criança. Isso contribui para uma melhor qualidade da atenção e do cuidado a ela dispensados.

É fundamental uma compreensão multifatorial e interdisciplinar sobre aspectos da infância por parte de seus cuidadores, para que se possa ter uma melhor atenção à sua saúde. Esta deve ser vista sob as mais diversas dimensões, seja fisiológica, psicológica ou social, em uma visão integral no contexto onde está inserida. Assim, faz-se necessária a implementação de múltiplas possibilidades de intervenções na assistência à criança, para um desenvolvimento pleno de possibilidades.

De acordo com a problemática citada e os resultados apresentados, percebemos o quão importante tem sido o projeto Ensinando a Crescer para os participantes.

As crianças pertencentes à camada menos favorecida da população já enfrentam diversos problemas muito antes do seu nascimento. Muitas, por exemplo, são vítimas de restrição de crescimento e desenvolvimento ainda na fase fetal, devido à própria condição socioeconômica familiar ou mesmo, por imprudência e/ou imperícia materna. Portanto, garantir a promoção à saúde destas crianças torna-se de grande valor.

Simultaneamente, através das oficinas realizadas mensalmente, proporcionamos um maior envolvimento entre pais e cuidadores de crianças, fortalecendo, assim, esse laço, fundamental para o bom desenvolvimento psíquico-moral dos pequeninos. Afinal, creche-escola é a segunda moradia deles!

Dessa forma, é fundamental que se dê continuidade a trabalhos como este, tentando atingir sempre ao maior número de pessoas.

\section{Agradecimentos}

Agradecemos à Universidade Federal do Ceará e à Pro-Reitoria de Extensão o apoio no desenvolvimento do Projeto de Extensão Ensinando a Crescer junto à comunidade de Barbalha.

Agradecimento especial a direção da Escola de Ensino Fundamental e Médio Maria da Dores Sampaio, por permitir o uso de suas instalações. 
Agradecemos também aos pais e cuidadores de crianças participantes do projeto que prontamente contribuíram com a realização do trabalho em questão.

\section{Referências}

BROWN, K. S. e FOLEN, R. A. Psychologists as Leaders of Multidisciplinary Chronic Pain Management Teams: A Model for Health Care Delivery. Professional Psychology: Research and Practice.2005, v. 36, n.6, p. 587-594.

CATTANI, Antonio David; KIELING, Francisco dos Santos. A escolarização das classes abastadas. Sociologias, Porto Alegre, n. 18, Dec. 2007.

FIGUEIRA, F; FERREIRA, O. S.; ALVES, J. G. B. Pediatria - instituto materno - infantil de Pernambuco (IMIP). Recife. Medsi. 2. ${ }^{\mathrm{a}}$ ed, 1996. 1596 p.

MARCONDES, Eduardo et al. Pediatria Básica: Pediatria Clínica Geral, 9. ${ }^{a}$ ed., São Paulo: Sarvier, 2003, 1006 p.

MELLO, A. Psicossomática e pediatria. In Júlio de Mello Filho (org.) Psicossomática hoje (pp. 195207). Porto Alegre: Artes Médicas, 1992.

NELSON W.E.; BEHRMAN R.E.; KLIEGMAN R.M.; JENSON H.B. Nelson: Tratado de Pediatria, 18. ${ }^{a}$ ed. Rio de Janeiro: Elsevier; 2009, 3568 p.

ORGANIZAÇÃO PANAMERICANA DE SAÚDE. Educación para la salud: un enfoque integral. Washington: OPS, 1995. (Série HSS/SILOS, n. 37).

PELICIONI, C. A escola promotora de saúde. São Paulo: Faculdade de Saúde Pública da Universidade de São Paulo, 1999. p.12. (Séries Monográficas)

SANTOS, Marcelo Justus dos; KASSOUF, Ana Lúcia. Uma investigação dos determinantes socioeconômicos da depressão mental no Brasil com ênfase nos efeitos da educação. Econ. Apl., Ribeirão Preto, v. 11, n. 1, Mar. 2007. 
http://idonline.emnuvens.com.br/id

ISSN on-line: 1981-1179

SULS, J. e ROTHMAN, A. Evolution of the Biopsychosocial Model: prospects and challenges for health psychology. Health Psychology, 2004, v.23, n.2, p. 119-125.

\section{Como citar este artigo (Formato ISO):}

FRANCO, T.A.; LUNA, G.H.S.A.; MATIAS, J.J.R.; GIFFONI, F.A.O.; GARCIA, J.S.B.L. Desenvolvimento infantil saudável: Projeto Ensinando a Crescer. Id on Line Revista de Psicologia, Fevereiro de 2014, vol.8, n.22, p. 10-17. ISSN 1981-1189.

Recebido: 15/01/2014

Aceito: 04/02/2014 